\title{
Pervaporative Desalination of Water Using Hydroxypropyl methylcellulose / Polyvinylpyrrolidone Blend Membranes
}

\author{
Derya UNLU \\ Bursa Technical University, Department of Chemical Engineering, 16310, Bursa, Turkey
}

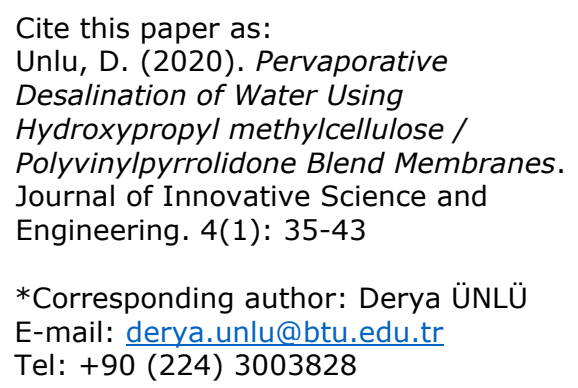

\section{cc) (i) (8)}

The works published in Journal of Innovative Science and Engineering (JISE) are licensed under a Creative Commons Attribution-NonCommercial 4.0 International License.

\begin{abstract}
The pervaporation is a promising process to achieve highly efficient desalination performance. In this study, Hydroxypropyl methylcellulose (HPMC) and Polyvinylpyrrolidone (PVP) polymers were chosen in the synthesis of blend membranes and used for pervaporative desalination process. The chemical structure and thermal stability of membranes were analyzed by using Fourier-transform infrared spectroscopy (FTIR) and Thermogravimetric analysis (TGA), respectively. The effects of PVP ratio in membrane and operation temperature on the flux and salt rejection were examined. The highest separation efficiency was acquired as water flux of $4.86 \mathrm{~kg} / \mathrm{m}^{2} \mathrm{~h}$ and a salt rejection of $99.9 \%$ using $50 \mathrm{wt} \% \mathrm{PVP}$ ratio at $40{ }^{\circ} \mathrm{C}$. The obtained results show that HPMC/PVP blend membrane has a great potential for water desalination via pervaporation.
\end{abstract}

Keywords: Desalination, Hydroxypropyl Methylcellulose, Membrane, Pervaporation, Polyvinylpyrrolidone. 


\section{Introduction}

Water is one of the most important substances for the sustainability of life on earth. Population growth, industrialization, urbanization causes a substantial increase in water consumption. To overcome water shortages, studies concentrate to obtain clean drinking water from saline water and recovery of treated industrial wastewater. Among them, the obtainment of fresh drinking water from saline water is a rather important application. This process is called as desalination [1-2].

The desalination processes have been generally conducted by thermal processes or the membrane processes. While Multi effect distillation (MED), Multi stage flash (MSF) are the thermal processes, Reverse osmosis (RO), Electrodialysis (ED) are the membrane based separation processes. Thermal processes are required high capital and operation cost. High energy consumption and high cost are main drawbacks of the thermal processes. The membrane processes are important alternatives to traditional separation methods for the desalination process. High separation efficiency, low energy consumption, green operation (without waste), easy installation are significant factors for the choosing of membrane processes. The most preferred of the membrane processes in desalination are the reverse osmosis and electrodialysis. Pervaporation is a rather important and innovative membrane process among membrane technologies [3-6].

In pervaporation, membrane permits the diffusion of component which has high solubility and diffusivity on the membrane surface. The transport in pervaporation occurs by solution-diffusion mechanism. This mass transfer mechanism comprises of three main stages: (a) sorption of the selective component onto the membrane, (b) diffusion of the selective component along the membrane, and (c) desorption of the selective component from the permeate side. The driving force of the pervaporation is vapor pressure difference. This force is created by applying low pressure at the permeate side while the feed side is under the atmospheric pressure [7-10].

Hydrophilic dense polymeric membranes such as cellulose, poly (vinyl alcohol), chitosan, poly (ether-blockamide), and sodium alginate are accepted the most suitable materials for the desalination by pervaporation. In spite of the high ion rejection of these membranes, the permeation flux was rather low and needed to be upgraded the flux value. Recently, blend membranes draw great interest due to the high hydrophilic features in pervaporation process [2]. In this study, HPMC and PVP were selected as membrane constituents. In addition, HPMC shows excellent film forming, biodegradability, and biocompatibility [11]. PVP has amide and carbonyl groups in the structure which are responsible for the hydrophilic structure of membrane. These groups provide the formation of hydrogen bond between membrane and water. The addition of PVP reduces the crystallinity degree of the polymeric membrane mixture and increases the diffusion gaps between the membrane matrix. This situation increases the sorption and diffusion degree and affects the separation performance [12].

In this study, HPMC/PVP blend membranes were synthesized and characterized by FTIR and TGA. Effects of PVP ratio in membrane and operation temperature on the separation efficiency were examined on salt rejection ratio and flux value. This study may contribute beneficial insights to improve high performance HPMC/PVP blend membranes for desalination via pervaporation. 


\section{Materials Methods}

\subsection{Materials}

Hydroxypropyl methyl cellulose (average $\mathrm{Mn} 10,000$ ) and Polyvinylpyrrolidone (K30, powder form) were purchased from Kimetsan and Sigma Aldrich, respectively. Sodium chloride ( $\mathrm{NaCl})(\sim 99 \%$ purity) was obtained from Merck. Acetone ( $\geq 99.0 \%)$, hydrochloric acid (37\%) and glutaraldehyde $\left(25 \%\right.$ in $\left.\mathrm{H}_{2} \mathrm{O}\right)$ were supplied by Sigma Aldrich.

\subsection{Preparation of HPMC/PVP Blend Membrane}

The blend membranes were fabricated via solution casting way. The membranes casting solutions were prepared by solving $10 \mathrm{wt}$ \% total polymers (HPMC and PVP) in water. HPMC/ PVP ratio in membrane solution was changed as 90/10, 70/30 and 50/50 wt.\%. The blend polymer solution was stirred to form a uniform solution. The prepared blend membrane solution was poured on a glass petri dish for drying at room conditions. Finally, the dry membrane was crosslinked in acetone/water mixture bath $(50 \% \mathrm{v} / \mathrm{v})$ containing the hydrochloric acid $(2.5 \mathrm{vol} . \%)$ and glutaraldehyde $(2.5$ vol. \%) for $3 \mathrm{~h}$.

\subsection{Characterization of HPMC/PVP Blend Membrane}

The chemical structure of membrane and interaction between HPMC and PVP were determined by using FTIR (Thermo Nicolet 5700 spectrometer). FTIR results were collected within a range of 400-4000 $\mathrm{cm}^{-1}, 4$ scans were recorded at 4 $\mathrm{cm}^{-1}$ resolutions. The thermal stability of membrane was specified using Mettler Toledo thermal analyzer. The degradation of membrane by temperature was determined in a heating rate of $10^{\circ} \mathrm{C} / \mathrm{min}$ with the temperature increasing from $25^{\circ} \mathrm{C}$ to $600^{\circ} \mathrm{C}$.

\subsection{Pervaporative Desalination of Water}

Water desalination tests were performed in pervaporation system which is represented in Figure 1. 


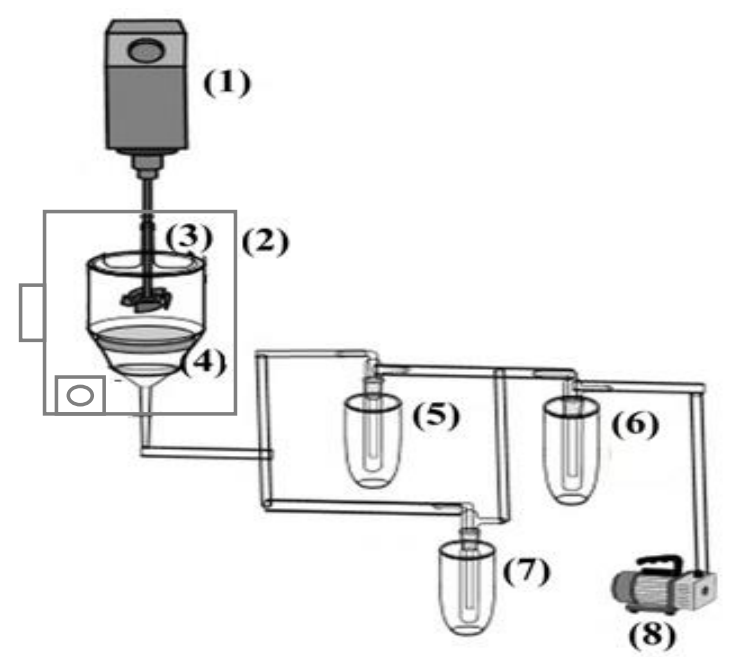

Figure 1. Pervaporation system: (1) mechanical agitator, (2) oven, (3) membrane chamber, (4) membrane, (5-7) cold traps, (8) vacuum pump

The blend membrane, with an active surface area of $9.62 \mathrm{~cm}^{2}$, was inserted in the membrane chamber. The synthetic saline water had been used in desalination experiments. The volume of membrane chamber was filled with NaCl-water solution. The desalination experiments were performed using fixed concentration of $5 \mathrm{wt} . \% \mathrm{NaCl}$. After the feed mixture was send to the membrane chamber, the solution was mixed continuously with the mechanical mixer to prevent possible mass transfer problems. The desalination experiments were performed under different temperature conditions (40, 50, 60, 70 ${ }^{\circ} \mathrm{C}$ ). The desired temperature was provided by using an oven. Membrane chamber was placed in the oven. Effect of PVP ratio on separation performance was also investigated in range of $10 \mathrm{wt} . \%$ to $50 \mathrm{wt} . \%$. Desalination tests were carried out for 5 hours. The feed mixture in the membrane chamber was kept at atmospheric pressure and the downstream side of the membrane chamber was kept at 5 mbar. The permeate fresh water was condensed in cold traps. The permeate stream samples were taken and analyzed by using the conductivity method. The performance of water desalination tests was determined by computing of flux and salt rejection. The flux was calculated by Equation 1,

$$
J=\frac{m}{A . t}
$$

where $\mathrm{J}$ is the flux, $\mathrm{m}$ is the permeation mass, $\mathrm{t}$ is the time and $\mathrm{A}$ is the active surface area of membrane.

The salt rejection is defined by Equation 2:

$$
R=\frac{C_{f}-C_{p}}{C_{f}} \times 100
$$

where $C_{f}$ and $C_{p}$ are the feed salt concentration and permeate salt concentration, $R$ is the rejection of salt capacity. 


\section{Results and Discussion}

\subsection{Characterization of membrane}

The chemical structure of pristine HPMC polymeric membrane and interaction between HPMC and PVP in blend membrane were determined by FTIR. The FTIR results of pristine HPMC membrane and blend HPMC/PVP membrane can be seen in Figure 2 .

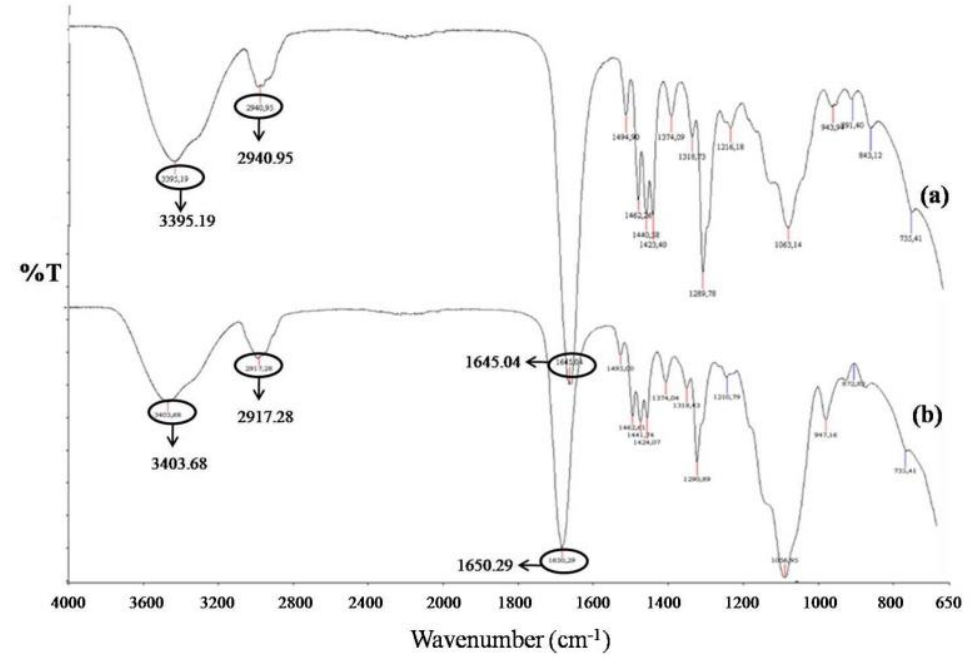

Figure 2. FTIR spectra of (a) Pristine HPMC membrane (b) HPMC/PVP blend membrane

The hydroxyl group in HPMC was observed in $3395.19 \mathrm{~cm}^{-1}$. The bands between 2940 and $2900 \mathrm{~cm}^{-1}$ could be attributed to the typical peaks of $\mathrm{CH}_{2}$ or $\mathrm{CH}_{3}$ groups in HPMC. A band appearing at $1645 \mathrm{~cm}^{-1}$ corresponds to $\mathrm{C}=\mathrm{O}$ groups of HPMC membrane [13]. The difference among the pristine HPMC membrane and blend membrane curves in Figure 2 was related to the interaction between the polymers. Therefore, a little shifting of the peak at $3403.68 \mathrm{~cm}^{-1}$ was observed in the transmission band of the HPMC/PVP blend membranes compared to the pristine HPMC membrane. The hydroxyl bands shifted to a lower wave number with the addition of PVP due to the strong hydrogen bindings between -OH groups of HPMC and $\mathrm{C}=\mathrm{O}$ groups of PVP [14].

The thermogravimetric analysis curve HPMC/PVP blend membrane is indicated in Figure 3. HPMC/PVP blend membrane had two decomposition stages in mass loss curves. The first stage due to the evaporation of absorbed water from membrane structure was observed in the temperature range of $25-150^{\circ} \mathrm{C}$. The second decomposition between temperature values of $300-450^{\circ} \mathrm{C}$ could be explained with the HPMC and PVP degradation. The melting point of HPMC was this temperature range. After the degradation of HPMC, PVP started the chemical decomposition in this temperature range. However, these degradation temperatures were rather higher than the process temperature in this study. Therefore, it has been found that the HPMC/PVP blend membrane is durable to operation temperatures for the pervaporative desalination process [15]. 


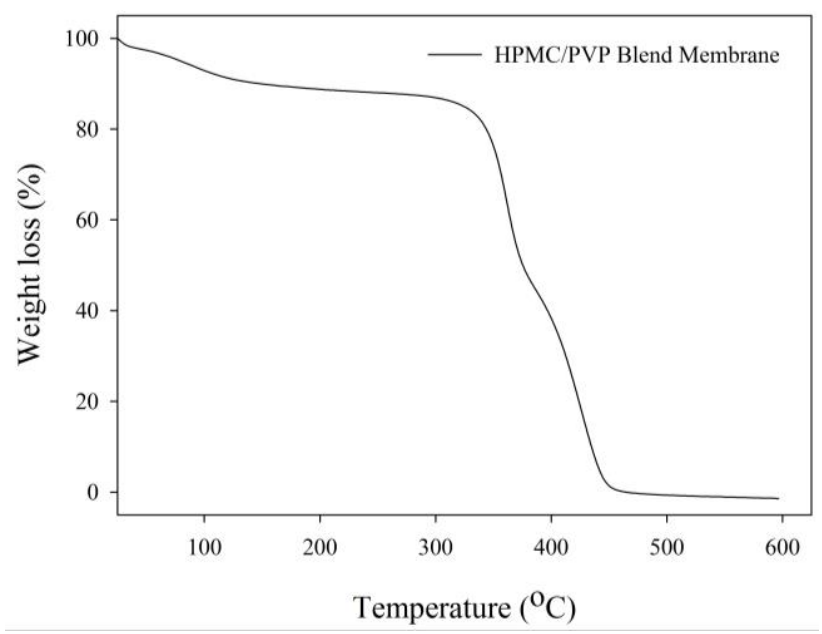

Figure 3. TGA curve of HPMC/PVP blend membrane

\subsection{Desalination Results}

Bending of polymer in synthesis of membrane is an efficient method for improving separation performance of membranes. For this purpose, to obtainment of high separation efficiency, PVP was added to the HPMC membranes. Figure 4 displays the influence of PVP ratio on the permeation flux and salt rejection. The influence of PVP ratio on separation efficiency of membrane was examined in the water- $\mathrm{NaCl}$ mixture containing $5 \mathrm{wt} . \% \mathrm{NaCl}$ at $40^{\circ} \mathrm{C}$.

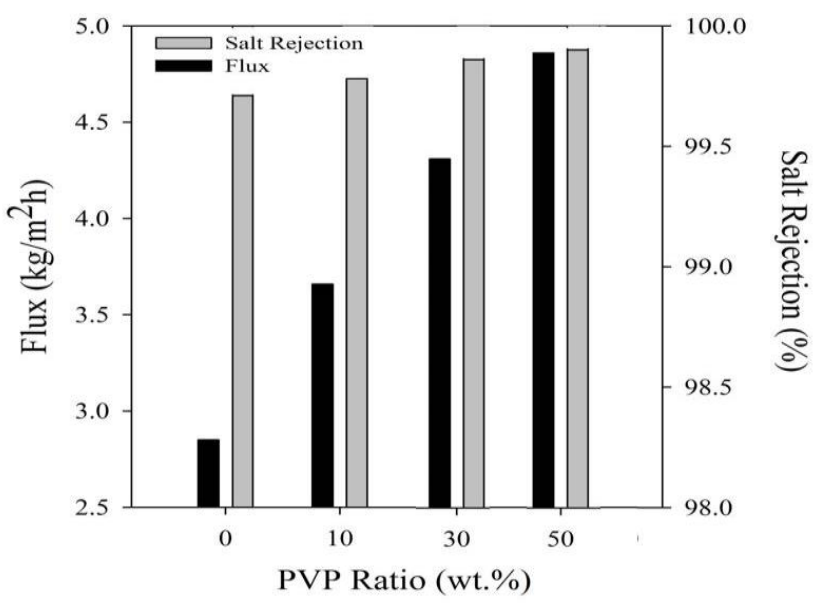

Figure 4. Effect of PVP ratio on flux and salt rejection

As it can be seen in Figure 4, the high PVP loading ratio is resulted in increment of permeation flux and salt rejection. The addition of PVP in HPMC significantly improved the hydrophilic feature of the membranes due to the strong polarity and hydrophilic properties of PVP. The interaction of between membrane and water increased and more hydrogen bonding formed. The affinity of membrane to water increased accordingly the sorption of water by the membrane increased [12, 16]. Consequently, both permeation flux and salt rejection were improved with the addition of PVP. The highest permeation flux and salt rejection values were acquired while the $50 \mathrm{wt} . \%$ PVP loaded membrane was used. PVP addition ratio was raised from $10 \mathrm{wt} . \%$ to $50 \mathrm{wt} . \%$, the salt rejection of the mixed matrix membrane and flux value increased from $99.71 \%$ to $99.9 \%$ and $2.85 \mathrm{~kg} / \mathrm{m}^{2} \mathrm{~h}$ to $4.86 \mathrm{~kg} / \mathrm{m}^{2} \mathrm{~h}$, respectively. 
The operation temperature performs a key function in the pervaporation. Temperature affects the solubility and diffusivity of components within the membrane. Thereby it considerably influences the separation efficiency of membranes. The influence of operation temperature on the separation efficiency is shown in Figure 5 for the PVP ratio in the membrane of $50 \mathrm{wt} . \%$. As the temperature raised from $40^{\circ} \mathrm{C}$ to $70^{\circ} \mathrm{C}$, the permeation fluxes increased, but the salt rejection was not significantly influenced by the temperature change, only a small fall was observed. The temperature rise increased the frequency and flexibility of the polymer chains. This flexibility causes expanded diffusion pathway within the membrane structure, resulting in easy transport of water along the membrane. In addition, the vapor pressure of feed side increased with temperature. However, the permeate side was not influenced by the temperature increment. This pressure differences were resulted in increment of the driving force. This accelerated the diffusion of water and led to high permeation flux [12, 16-17]. While the flux increased from $4.86 \mathrm{~kg} / \mathrm{m}^{2} \mathrm{~h}$ to $5.87 \mathrm{~kg} / \mathrm{m}^{2} \mathrm{~h}$, the salt rejection decreased from 99.9 to 99.18 with an increase in the temperature from $40^{\circ} \mathrm{C}$ to $70^{\circ} \mathrm{C}$.

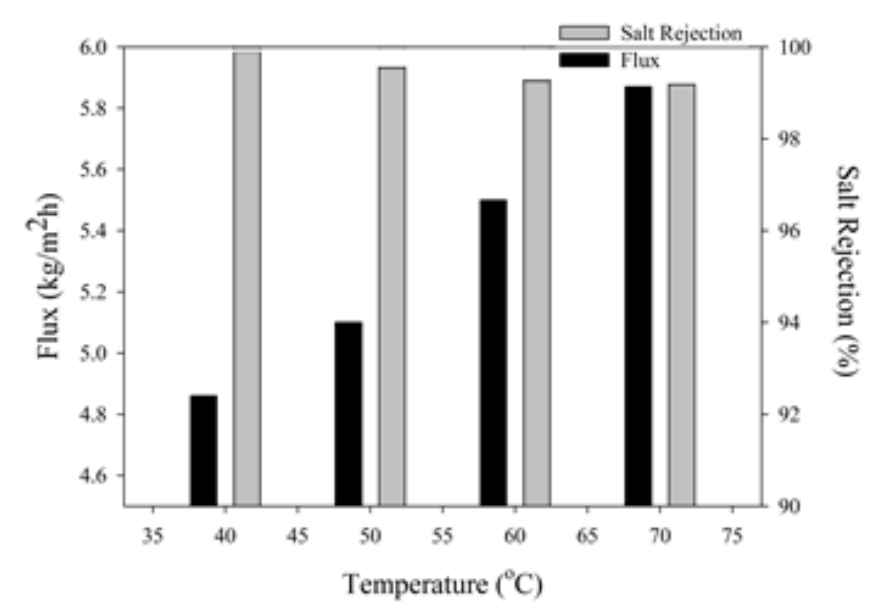

Figure 5. Effect of temperature on flux and salt rejection

\section{Conclusion}

The blend membranes were prepared by mixing HPMC with Polyvinylpyrrolidone. The chemical structure of pristine HPMC membrane and interaction between HPMC and PVP polymers were revealed by FTIR. TGA results showed that HPMC/PVP blend membrane had sufficient thermal stability for pervaporative desalination process. The HPMC/PVP blend membrane showed good performance in pervaporative desalination. The addition of PVP in HPMC membrane had increased the hydrophilicity of the membranes and the permeation flux. As the PVP ratio in blend membranes increased from 0 to $50 \mathrm{wt}$. $\%$, the permeation flux increased, but the salt rejection was not affected by this situation. Of all the prepared blend membranes, $50 \mathrm{wt}$ \% PVP content blend membrane was exhibited the best separation performance. The optimum process temperature was determined as $40^{\circ} \mathrm{C}$, because salt rejection value decreased a little at the higher temperatures than the $40^{\circ} \mathrm{C}$. The highest salt rejection and the permeate flux were $99.9 \%$ about and $4.86 \mathrm{~kg} /\left(\mathrm{m}^{2} \mathrm{~h}\right)\left(40^{\circ} \mathrm{C}\right.$, $50 \mathrm{wt} . \%$ PVP ratio), respectively. The acquired results also showed that the HPMC/PVP blend membrane had excellent desalination performances by pervaporation. 


\section{References}

[1] Huth E., Muthu S., Ruff L., Brant J. (2014). Feasibility Assessment of Pervaporation for Desalinating HighSalinity Brines. Journal of Water Reuse \& Desalination, 4(2): 109-124.

[2] Selim, A., Toth, J.A., Haaz, E., Fozer, D., Szanyi, A., Hegyesi, N., Mizsey, P. (2019). Preparation and characterization of $\mathrm{PVA} / \mathrm{GA} / \mathrm{Laponite}$ membranes to enhance pervaporation desalination performance. Separation and Purification Technology, 221:201-210.

[3] Assabumrungrat, S., Phongpatthanapanich, J., Praserthdam, P., Tagawa, T., Goto, S. (2003). Theoretical study on the synthesis of methyl acetate from methanol and acetic acid in pervaporation membrane reactors: effect of continuous-flow modes. Chemical Engineering Journal, 95(1-3): 57-65.

[4] Park, B.G., Tsotsis, T.T. (2004). Models and experiments with pervaporation membrane reactors integrated with an adsorbent system. Chemical Engineering and Processing: Process Intensification, 43(9):1171-1180.

[5] Unlu, D., Hilmioglu, N.D. (2014). Pervaporation catalytic membrane reactor study for the production of ethyl acetate using $\mathrm{Zr}(\mathrm{SO} 4) 2.4 \mathrm{H} 2 \mathrm{O}$ coated chitosan membrane. Journal of Chemical Technology and Biotechnology, 91(1):122-130.

[6] Kavitha, J., Rajalakshmi, M., Phani, A.R., Padaki, M. (2019). Pretreatment processes for seawater reverse osmosis desalination systems-A review. Journal of Water Process Engineering, 32:100926.

[7] Huang, R.Y.M. (1991). Pervaporation Membrane Separation Processes, Elsevier, Science Publishers BV, Amsterdam, 1st Edition, 549 p. ISBN-0444882278.

[8] Smitha, B., Suhanya, D., Sridhar, S., Ramakrishna, M. (2004). Separation of organic-organic mixtures by pervaporation - a review. Journal of Membrane Science, 241(1):1-21.

[9] Wijmans, J. G., Baker R. W. (1995). The solution-diffusion model: a review. Journal of Membrane Science, 107(1-2):1-21.

[10] Austria, H.F.M., Lecaros, R.L.G., Hung, W.-S., Tayo, L.L., Hu, C.-C., Tsai, H.-A., Lai, J.-Y. (2019). Investigation of salt penetration mechanism in hydrolyzed polyacrylonitrile asymmetric membranes for pervaporation desalination. Desalination, 463:32-39.

[11] Venkatesulu, G., Babu, P.K., Maruthi, Y., Rao, U.S.K., Subha, M.C.S., Rao, K.C. (2016). Composite Membranes Comprising of Hydroxypropyl Cellulose - Poly(VinylAlcohol) Incorporated with Inorganic Fillers for Dehydration of Ethanol by Pervaporation. Journal of Advanced Chemical Sciences, 2(1): 174-179.

[12] Zhang, X.H., Liu, Q.L., Xiong, Y., Zhu, A.M., Chen, Y., Zhang, Q.G. (2009). Pervaporation Dehydration of Ethyl Acetate/Ethanol/Water Azeotrope Using Chitosan/Poly (vinyl pyrrolidone) Blend Membranes. Journal of Membrane Science, 327:274-280.

[13] Guirguis, O.W., Moselhey, M.T.H. (2011). Optical study of poly(vinyl alcohol)/hydroxypropyl methylcellulose blends. Journal of Materials Science, 46(17):5775-5789.

[14] Rao, K.C., Subha, M.C.S., Reddy, C.S., Babu, P.K., Sudhakar, K., Prabhakar, M.N., Maruthi, Y., and U. Rao, U.S.K. (2013). Miscibility Studies of Hydroxyethyl Cellulose and Poly (Vinylpyrrolidone) Blends. International Journal of Basic and Applied Chemical Sciences, 3(1): 73-83.

[15] Elkader, M.F.H.A., Abu-Abdeen, M. (2012). Thermal and Mechanical Studies of PVP/2-HEC Blend Films. Australian Journal of Basic and Applied Sciences, 6(13): 454-462. 
[16] Zhu, T., Luo, Y., Lin, Y., Li, Q., Yu, P., Zeng, M. (2010). Study of pervaporation for dehydration of caprolactam through blend NaAlg-poly(vinyl pyrrolidone) membranes on PAN supports. Separation and Purification Technology, 74(2):242-252.

[17] Ding, M., Xu, H., Chen, W., Yang, G., Kong, Q., Ng, D., Xie, Z. (2020). 2D laminar maleic acid-crosslinked MXene membrane with tunable nanochannels for efficient and stable pervaporation desalination. Journal of Membrane Science, 600: 117871. 